\title{
Phase Change Energy Storage with Composite Plates Optimized Structure for Maximizing Energy Storage Potentials
}

\author{
Chengqiang YAO \\ School of Energy and Environment Engineering \\ Hebei University of Technology \\ Tianjin, China \\ Chengying QI \\ School of Energy and Environment Engineering \\ Hebei University of Technology \\ Tianjin, China \\ Hua YANG \\ School of Energy and Environment Engineering \\ Hebei University of Technology \\ Tianjin, China
}

\author{
Xiangfei KONG \\ School of Energy and Environment Engineering \\ Hebei University of Technology \\ Tianjin, China \\ E-mail: nesta7603@126.com
}

Minchao FAN

School of Energy and Environment Engineering Hebei University of Technology

Tianjin, China

\section{Xin XU}

School of Energy and Environment Engineering Hebei University of Technology

Tianjin, China

\begin{abstract}
The vacuum absorption method was used to fabricate the phase change material particle (PCMP) in a vacuum heating roller box, and then PCMPs were pressed to form the composite phase change energy storage plate (CPCESP) through a mould. Tests about the thermal conductivity and the heat storage and release capacity of CPCESP with different aluminum (Al) mass fractions were conducted; meanwhile, their fitting curves were obtained. According to the linear optimization principle and different actual situations, Al mass fractions, thermal conductivity and heat storing and discharge capacity per unit mass for CPCESP can be achieved, in order to optimize CPCESP heat storage and release performance.
\end{abstract}

Keywords-composite phase change energy storage plate; thermal conductivity; heat storage and release capacity; linear optimization

\section{INTRODUCTION}

As people's living standards improving, building energy consumption is showing a trend of increase in recent years [1-2]. According to the statistics, the proportion of building energy consumption has more than one third of China's total energy consumption[3]. With the advent of the energy crisis, people are increasingly concerned about the energy storage and utilization[4-6].

Adding phase change material (PCM) into building substrate and applying them to building envelopes can achieve the goal of energy saving, consumption reducing and temperature regulating[7]. However, due to the limitations of current technology, PCM is difficult to achieve large-scale production, which restricts its application in large constructions. In addition, PCM itself has shortcomings of not-high heat conductivity coefficient and the value directly relates to the heat storage and release rate of $\mathrm{PCM}[8]$. Adding excellent heat conductivity additives (such as copper, nickel, aluminum, etc.) to enhance the performance of phase change thermal energy storage material becomes a problem to be solved when applying phase change energy storage technology[9]. If excessive additives will reduce the heat storage and release ability, how to balance the amount of additives with high thermal conductivity performance and phase change material becomes a difficult point of the study.

In this paper, paraffin was used as the phase change material, porous medium expanded perlite (EP) as the adsorbent material[10]. Using vacuum heating roller box which can achieve large-scale PCMP production, then PCMPs were pressed into CPCESP through compression molding method. The effect of the different ratios of the aluminum content to the thermal conductivity and storage heat quantity per unit mass was determined, the equation of linear regression of the thermal conductivity and heat storage quantity per unit mass was linearly fitted out. Finally, based on linear optimization principle, the calculation method of optimizing the heat storage and release capacity of CPCESP was obtained.

\section{EXPERIMENTAL}

\section{A. Experimental Materials and Instruments}

Main raw materials and instruments used in the experiments are shown in Tab. 1. 
TABLE I. EXPERIMENTAL MATERIALS AND INSTRUMENTS

\begin{tabular}{|c|c|c|}
\hline Material/Instrument & Model & Accuracy \\
\hline Expanded perlite & $50-60$ mesh & - \\
\hline Paraffin & $25 \#$ & - \\
\hline Styrene acrylic emulsion & $7199 \mathrm{~A}$ & - \\
\hline Al & 600 mesh & - \\
\hline Glass fiber & $6 \mathrm{~mm}$ & $\leq \pm 0.01 \mathrm{~g}$ \\
\hline Electronic balance & ME2002 & - \\
\hline Circulating water vacuum pump & SHZ-D $(111)$ & - \\
\hline Vacuum heating roller box & - & - \\
\hline Electric thermostatic drying oven & 101 & - \\
\hline DSC & TADSC2910 & $\leq 0.0041 \%$ \\
\hline Thermal conductivity meter & HFM436 & $\leq \pm 0.1{ }^{\circ} \mathrm{C}$ \\
\hline Data logger & Agilent 34972A & $\leq 5 \%$ \\
\hline Thermocouple & T-type & WYP \\
\hline Thermal flux sensor & & \\
\hline
\end{tabular}

\section{B. Preparation of CPCESP}

(1) Weighed the expanded perlite and paraffin in the mass ratio $1: 1.2$ by electronic balance, then put them in the vacuum heating roller box and vacuumize the box, and next heated the box to $50^{\circ} \mathrm{C}$.

(2) Set the roller box at a uniform rotation at 100 $\mathrm{rad} / \mathrm{min}$, after $4 \mathrm{~h}$, the preparation of PCMPs was finished.

(3) Added PCMPs, styrene acrylic emulsion, glass fiber and aluminum powder into the blender, the mass fraction of each substance was shown in Tab. 2, then started the blender to stir uniformly.

(4) Poured the well stirred mixture into the prefabricated mould, compressed in certain shape then put them into the drying oven. After drying, the size of $0.5 \mathrm{~m} \times 0.5 \mathrm{~m} \times 0.02 \mathrm{~m}$ composite phase change energy storage plate was prepared.

TABLE II. MASS FRACTION OF CPCESP

\begin{tabular}{|c|c|c|c|}
\hline PCMP & $\begin{array}{c}\text { Styrene acrylic } \\
\text { emulsion }\end{array}$ & Glass fiber & $\begin{array}{c}\text { Aluminum } \\
\text { powder }\end{array}$ \\
\hline $80 \%-90 \%$ & $9.5 \%$ & $0.5 \%$ & $0 \%-10 \%$ \\
\hline
\end{tabular}

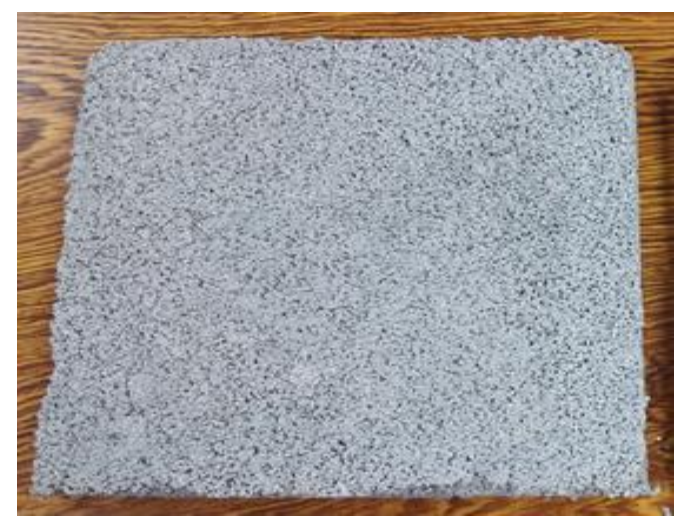

Figure 1. Composite phase change energy storage plate.

\section{Property Characterization of CPCESP}

Differential scanning calorimeter (DSC) (TADSC2910 model) was used to test thermal performance of the PCMPs from CPCESP, in nitrogen atmosphere, over the range of 0$50^{\circ} \mathrm{C}$ at a heating rate of $5^{\circ} \mathrm{C} / \mathrm{min}$, melting and solidification curves were obtained, which provided theory basis to the heat storage calculation of the plate and PCM content. Heat conductivity coefficient of CPCESP was measured by conductometer (HFM436) under different aluminum content conditions to analyze the thermal conductivity.

\section{Heat Storage and Release Capacity Test of CPCESP}

Heat storage and discharge capacity testing system consists of a closed cabinet, two thermostatic water baths, five thermocouples and two thermal flux sensors. The closed cabinet is a cube with side length $360 \mathrm{~mm}$, which is composed of $30 \mathrm{~mm}$ thick double layer polystyrene board, with polyurethane foam filling the gap. Aluminum foil tape was posted outside the enclosed space so as to play a role of thermal insulation.

The thermostatic water bath provided a hot and cold sources between $15^{\circ} \mathrm{C}$ to $35^{\circ} \mathrm{C}$ for the enclosed space to simulate plate under hot and cold environment, then heat storage and release capacity of CPCESP in different temperature conditions was tested. The plate was placed in the center of confined space, two cooling devices of the thermostatic water bath were installed on both sides providing both high and low temperature heat source. The thermal flux sensors were attached to the left and right sides of the plate, detecting the heat flow, thus calculated heat storage and release quantity of the CPCESP. Five thermocouples were arranged on both sides of the plate, in the center of the plate and in both sides of the confined space respectively. Next, thermal flux sensor and thermocouples were connected to Agilent data logger to monitor the change of heat flow and temperature. The main operation steps are listed as follows:

(1) Turned on the Agilent data logger and thermostatic water bath, and set water bath temperature at $15^{\circ} \mathrm{C}$. When the temperature of thermocouple which is placed in the center of the plate remained stable, the testing system was considered to reach steady state in low temperature.

(2) Reset the Agilent data logger and set the water bath temperature at $35^{\circ} \mathrm{C}$, as the water bath temperature rising, cooling devices dissipated heat to the confined space to make the plate phase change to store heat. When the plate temperature was basically stable and the thermal flux on both sides was less than $1.5 \mathrm{~J} /(\mathrm{m} 2 \cdot \mathrm{k})$, the plate was considered to be fully endothermic.

(3) Set the water temperature at $15{ }^{\circ} \mathrm{C}$, to simulate the heat release stage, similarly, when the plate temperature was basically stable and thermal flux on both sides was less than $1.5 \mathrm{~J} /(\mathrm{m} 2 \cdot \mathrm{k})$, the plate was fully exothermic.

(4) Calculated heat storage quantity by the integral of the heat flow. 


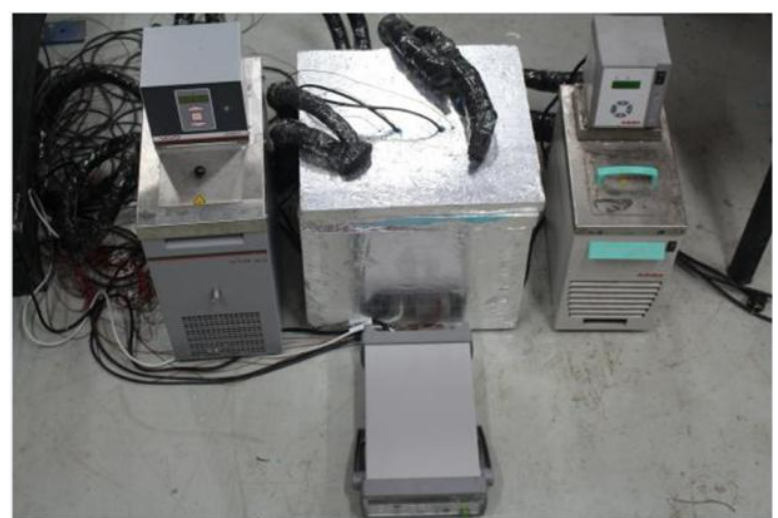

Figure 2. Heat storage capacity testing system.

\section{RESUlTS AND DISCUSSION}

\section{A. Thermal Property Analysis of CPCESP}

Differential scanning calorimeter (DSC) test was conducted on CPCESP and DSC curve is shown in Fig. 3. As can be seen from Fig. 3, the freezing point of the PCMP is $24.34^{\circ} \mathrm{C}$, and peak temperature of freezing is $23.98^{\circ} \mathrm{C}$; melting point was $24.89^{\circ} \mathrm{C}$, peak temperature of melting is $26.38^{\circ} \mathrm{C}$ and the latent heat is $74.52 \mathrm{~J} / \mathrm{g}$. Although the measured latent heat of PCMP is lower than the theoretical latent heat, it is still of great application value.

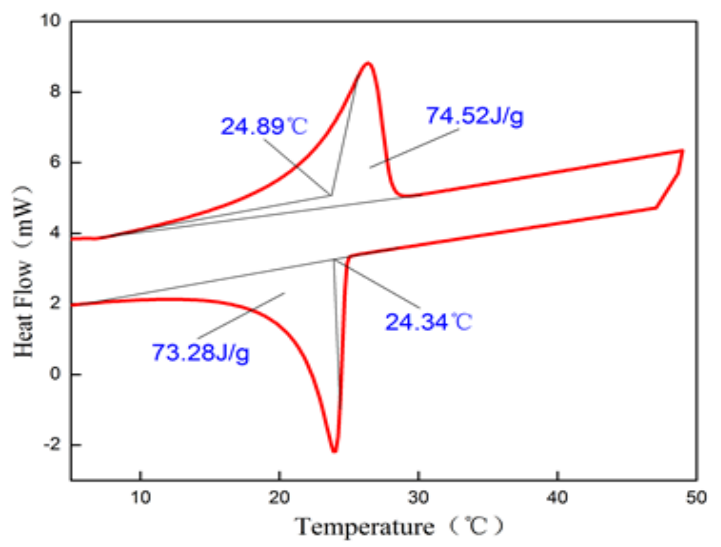

Figure 3. DSC curves of PCMP.

\section{B. Thermal Conductivity Coefficient Analysis of CPCESP}

Thermal conductivity meter(HFM436) was used to test the thermal conductivity coefficient of CPCESP under the mean temperature difference around $20^{\circ} \mathrm{C}$ at the aluminum content of $0 \%, 2 \%, 4 \%, 5 \%, 6 \%, 8 \%, 10 \%$ respectively. The results are shown in Tab. 3 .

TABLE III. THERMAL CONDUCTIVITY COEFFICIENT OF PLATE IN DIFFERENT ALUMINUM CONTENT

\begin{tabular}{|c|c|c|c|c|c|c|c|}
\hline $\begin{array}{c}\text { Al } \\
\text { content } \\
(\%)\end{array}$ & $\mathbf{0}$ & $\mathbf{2}$ & $\mathbf{4}$ & $\mathbf{5}$ & $\mathbf{6}$ & $\mathbf{8}$ & $\mathbf{1 0}$ \\
\hline $\begin{array}{c}\text { Thermal } \\
\text { conductiv } \\
\text { ity } \\
(\mathbf{W} / \mathbf{m} \cdot \mathbf{k})\end{array}$ & $\begin{array}{c}0.130 \\
9\end{array}$ & $\begin{array}{c}0.131 \\
3\end{array}$ & $\begin{array}{c}0.134 \\
1\end{array}$ & $\begin{array}{c}0.135 \\
2\end{array}$ & $\begin{array}{c}0.137 \\
5\end{array}$ & $\begin{array}{c}0.142 \\
5\end{array}$ & $\begin{array}{c}0.143 \\
5\end{array}$ \\
\hline
\end{tabular}

From Tab. 3, at the mean temperature difference around $20^{\circ} \mathrm{C}$, the thermal conductivity coefficient rises with the increase of aluminum content. The measured data distribute in a straight line in the vicinity and thermal conductivity coefficient of other aluminum content can be obtained through the linear fitting. Fitting curves and formulas of thermal conductivity coefficient of the plate are shown in Fig. 4.

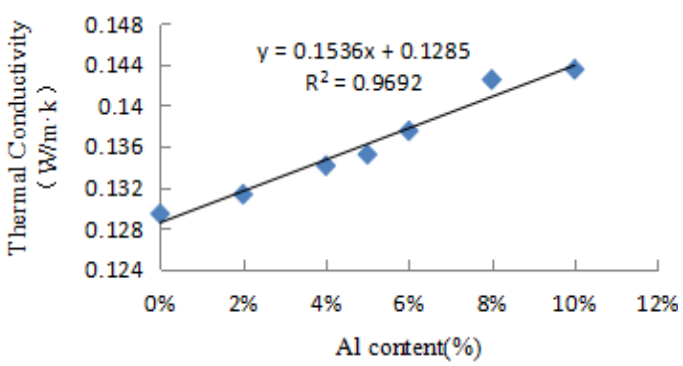

Figure 4. The thermal conductivity coefficient fitting curve of different aluminum content plate.

Temperature changes of CPCESP in the exothermic process under $20-27^{\circ} \mathrm{C}$ at the aluminum content $0 \%, 5 \%$, $10 \%$ were monitored. From the results shown in Fig. 5, temperature rising rate of the plates which contain $10 \%$ and $5 \%$ aluminum between $20^{\circ} \mathrm{C}$ and $24.5^{\circ} \mathrm{C}$ had no big difference. However, when the temperature reached to $24.5^{\circ} \mathrm{C}$, difference of temperature rising rate of the two plates increased gradually. What's more, the temperature rising rate of the plate with aluminum powder was much greater than the plate without aluminum powder, which means high thermal conductivity performance aluminum powder enhanced the thermal conductivity coefficient of CPCESP to make it more sensitive to temperature response.

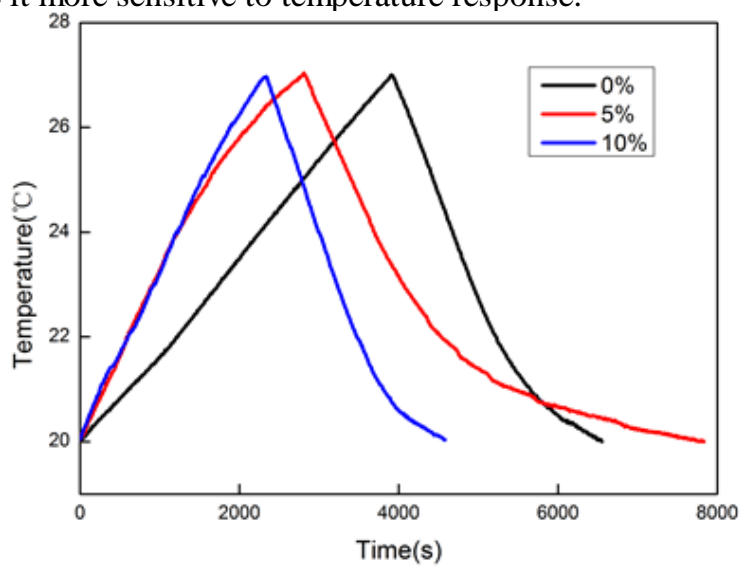

Figure 5. The temperature curves of different aluminum content.

\section{Heat Storage and Release Capacity Analysis of CPCESP}

By using the testing devices demonstrated in Fig. 2, heat storage and release capacity of CPCESP in different aluminum content was measured. The side length of the test plate is $0.23 \mathrm{~m}$, thickness $0.02 \mathrm{~m}$, total area $0.0529 \mathrm{~m}^{2}$ and the results are shown in Tab. 4 . 
TABLE IV. HeAt Storage AND RELEASE QuANTITY OF DiFFERENT ALUMINUM CONTENT PLATE

\begin{tabular}{|c|c|c|c|}
\hline $\begin{array}{c}\text { Al content } \\
(\mathbf{\%})\end{array}$ & Mass(g) & $\begin{array}{c}\text { Heat storage } \\
\text { quantity per } \\
\text { unit area }\left(\mathbf{J} / \mathbf{m}^{2}\right)\end{array}$ & $\begin{array}{c}\text { Heat release } \\
\text { quantity per } \\
\text { unit } \\
\text { area( }\left(\mathbf{J} / \mathbf{m}^{2}\right)\end{array}$ \\
\hline $\mathbf{0}$ & 524.03 & 551865.99 & 524723.42 \\
\hline $\mathbf{2}$ & 523.81 & 522027.66 & 520641.40 \\
\hline $\mathbf{4}$ & 524.19 & 518541.83 & 511803.66 \\
\hline $\mathbf{5}$ & 524.42 & 517282.34 & 481792.29 \\
\hline $\mathbf{6}$ & 523.90 & 500428.34 & 468340.85 \\
\hline $\mathbf{8}$ & 525.08 & 494905.27 & 455003.16 \\
\hline $\mathbf{1 0}$ & 525.21 & 469611.21 & 458292.88 \\
\hline
\end{tabular}

In order to study the influence of aluminum content on the heat storage and release capacity, total heat storage and release quantity of the tested plate should be calculated first and then the heat storage and release quantity per unit mass. The formula is shown as follows:

$$
Q_{z}=Q^{*} \times A
$$

where $\mathrm{Q}_{\mathrm{z}}$ is the total heat storage and release quantity of the tested plate, $\mathrm{Q}^{*}$ is the heat storage and release quantity per unit mass, $\mathrm{A}$ is the area of the tested plate.

$$
q=Q_{z} / m
$$

where $\mathrm{q}$ is the heat storage and release quantity per unit mass of the tested plate, $\mathrm{m}$ is the mass of the tested plate.

Heat storage and release quantity per unit mass of different aluminum content plate can be calculated by (1) and (2) and the results are listed in Tab. 5.

TABLE V. HEAT Storage AND RelEASE QuANTITy PER UNit MASS

\begin{tabular}{|c|c|c|c|}
\hline $\begin{array}{c}\text { Al } \\
\text { content } \\
(\boldsymbol{\%})\end{array}$ & $\begin{array}{c}\text { Heat storage } \\
\text { quantity per } \\
\text { unit area(J/g) }\end{array}$ & $\begin{array}{c}\text { Heat storage } \\
\text { quantity per } \\
\text { unit area(J/g) }\end{array}$ & $\begin{array}{c}\text { Average heat } \\
\text { storage and release } \\
\text { quantity per unit } \\
\text { area(J/g) }\end{array}$ \\
\hline $\mathbf{0}$ & 55.71 & 52.97 & 54.34 \\
\hline $\mathbf{2}$ & 52.72 & 52.58 & 52.65 \\
\hline $\mathbf{4}$ & 52.33 & 51.65 & 51.99 \\
\hline $\mathbf{5}$ & 52.18 & 48.60 & 50.39 \\
\hline $\mathbf{6}$ & 50.53 & 47.29 & 48.91 \\
\hline $\mathbf{8}$ & 49.86 & 45.84 & 47.85 \\
\hline $\mathbf{1 0}$ & 47.30 & 45.02 & 46.16 \\
\hline
\end{tabular}

Linear fitting on the average heat storage and release quantity per unit mass of different aluminum content plate was made and fitting curve is demonstrated in Fig. 6.

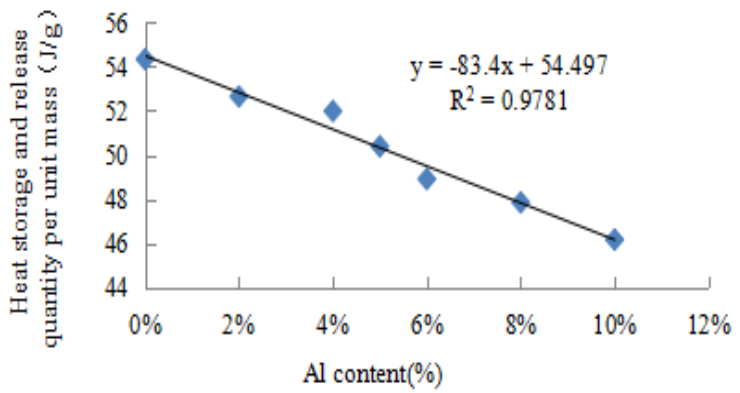

Figure 6. Fitting curve of heat storage and release quantity per unit mass.

\section{Optimization Analysis of the Heat Storage and Release Performance}

Fig. 4 and Fig. 6 are the linear fitting curves and equations on the CPCESP thermal conductivity coefficient and heat storage and release quantity per unit mass to the aluminum content. From the figures, the thermal conductivity coefficient of CPCESP and aluminum content were approximately positively correlated, which means the addition of aluminum powder improves the thermal conductivity performance of the plate and the greater the content, the better the heat conducting property. However, the heat storage and release quantity per unit mass decreases with the increase of aluminum content, because the heat storage and release capacity of the aluminum powder is far worse than PCMPs. Equations on the CPCESP thermal conductivity coefficient and heat storage and release quantity per unit mass to the aluminum content are as follows:

$$
\begin{aligned}
& \lambda=0.1536 w+0.1285, R^{2}=0.9692 \\
& q=-83.4 w+54.497, R^{2}=0.9781
\end{aligned}
$$

where $\lambda$ is the thermal conductivity coefficient of the tested plate, $w$ is the aluminum content of the tested plate.

According to the linear optimization theory, the heat storage performance is optimized to the solutions of the two equations (3) and (4) under a given constraint. Based on the thermodynamic specification, thermal parameters of the $140 \mathrm{~mm}$ thick cement and EP insulation wall are shown in Tab. 6. The hottest day in 2015 of the summer in Tianjin region is chosen as a typical day, building indoor temperature was set at $26{ }^{\circ} \mathrm{C}$, and calculation formula of the wall's heat transfer is as follows:

$$
Q=K F \Delta t_{\tau-\varepsilon}
$$

where $\mathrm{Q}$ is the heat absorption of the chosen wall, $\mathrm{K}$ is the heat transfer coefficient, $\mathrm{F}$ is the area of the tested wall, $\tau-\varepsilon$ is the time of temperature wave acting on the wall surface, $\Delta t_{\tau-\varepsilon}$ is the temperature difference at the acting moment. 
TABLE VI. Thermal PARAMETERS OF THE CALCULATED WALL

\begin{tabular}{|c|c|c|c|c|}
\hline $\begin{array}{c}\text { Heat } \\
\text { transfer } \\
\text { coefficient } \\
\mathbf{K}\end{array}$ & $\begin{array}{c}\text { Attenuation } \\
\text { coefficient } \\
\boldsymbol{\beta}\end{array}$ & $\begin{array}{c}\text { Attenuati } \\
\text { on degree } \\
\mathbf{v}\end{array}$ & $\begin{array}{c}\mathbf{L a g} \\
\text { time } \\
\boldsymbol{\varepsilon}(\mathbf{h})\end{array}$ & $\begin{array}{c}\text { Exothermic } \\
\text { attenuation } \\
\text { degree vf }\end{array}$ \\
\hline 0.58 & 0.16 & 86.48 & 12.8 & 1.2 \\
\hline
\end{tabular}

According to (5) and the outdoor meteorological parameters in Tianjin region, the hourly heat transfer quantity was calculated, then through integral, heat quantity absorbed by the wall in one day's time per unit area can be obtained as $518400 \mathrm{~J}$. Assume that $0.02 \mathrm{~m}$ thick CPCESP is used to accumulate these heat, as the density of the plate is around $495.3 \mathrm{Kg} / \mathrm{m}^{3}$, the plate quality used on wall per unit area will be $9906 \mathrm{~g}$ and the heat storage quantity will be $52.33 \mathrm{~J} / \mathrm{g}$. Taking the above results in to equation (3) and (4), aluminum content of the plate can be calculated as $2.6 \%$ and the heat conductivity coefficient as $0.1325(\mathrm{~W} / \mathrm{m} \cdot \mathrm{k})$. Such design can not only meet the requirements of heat storage per unit mass, but also optimize the heat storage and release rate to the fastest.

The significance of using linear optimization method to optimize the heat storage and release properties of CPCESP lies in the use of theoretical calculation to determine the aluminum content, heat conductivity coefficient and heat storage and release quantity per unit mass of the plate to achieve the its optimal performance.

\section{CONClusions}

(1) The heat conducting properties of CPCESP are enhanced by adding high thermal conductivity aluminum powder and the thermal conductivity coefficient of plate is approximately positively correlated to the aluminum content. According to the measured data, the fitting curve of thermal conductivity coefficient and aluminum content can be obtained.

(2) The heat storage capacity of CPCESP is affected by the aluminum content, the higher the aluminum content, the worse the heat storage performance. According to the heat accumulation of the plate per unit mass, he fitting curve of heat accumulation per unit mass and aluminum content can be obtained.

(3) Based on the linear optimization principle, theoretical calculations can be conducted according to the different situation. Then the aluminum content, thermal conductivity coefficient and heat accumulation per unit mass of the certain plate can be solved to optimize its heat storage and release properties.

\section{ACKNOWLEDGMENTS}

This work was supported by National Natural Science Foundation of China (Project No.51408184), Tianjin Natural Science Foundation (Project No. 15JCQNJC07800), Outstanding Youth Fund Projects in Hebei Province Department of Education (Project No. YQ2014005).

\section{REFERENCES}

[1] Kong X F, Lv S L, Gao P, et al. Research on the energy performance and Indoor environment quality of typical public buildings in the tropical areas of China [J].Energy and Buildings,2012,(48):155-167.

[2] Kong X F, Lv S L, Wu Y. A review of building energy efficiency in China during "Eleventh Five-Year Plan" period[J]. Energy Policy, 2012,(41):624-635.

[3] Building energy conservation research center, Tsinghua University, China Building Energy Efficiency Annual Development Report 2011 [M]. Beijing: China building industry press, 2011.

[4] Ferrer G, Solé A, Barreneche C, et al. Corrosion of metal containers for use in PCM energy storage[J]. Renewable Energy, 2015,(76):465469.

[5] Felix A, Solanki C , Saini J. Heat Transfer Characteristics Of Thermal Energy Storage System Using Pcm Capsules: A Review[J]. Renewable \& Sustainable Energy Reviews, 2008, 12(9):2438-2458.

[6] AugustynV, Simon P, Dunn B.Pseudocapacitive oxide materials for high-rate electrochemical energy storage $[\mathrm{J}]$. Energy \& Environmental Science, 2014, 7(5): 1597-1614.

[7] Zeng Lingke, Wang Hui, Xiao Sucheng, Liu Pingan, Zhu Yuanyuan. Preparation and properties of phase change energy-storing gypsum research [J]. Journal of new building materials, 2012, 12:27-29.

[8] DoCoutoAktay, K.S., R. Tamme and H. Müller-Steinhagen, Thermal conductivity of high-temperature multicomponent materials with phase change. International Journal of Thermophysics, 2008. 29(2): p. 678-692.

[9] Yang Fei. Building energy efficiency with phase change energy storage material thermal physical property research [D]. Chongqing University, 2014.

[10] Zhi-yu Wang, Xian-ping Fan, Guo-dong Qian, Wei-ping Shi, Lu-bao Liu, Xiao-shan Wang, HuaRuan. Phase change paraffin composite expanded perlite insulation mortar powder [J]. Journal of building materials development direction, 2009. 